\title{
Editorial
}

\section{Progress in Surgical-Site Infection Surveillance}

\author{
Richard Platt, MD, MSc
}

How many surgical-site infections (SSIs) occurred last year in the United States? Were there more or fewer than 5 years ago? If more, could we have done better? If fewer, could we have done better still?

It has been more than 25 years since the Centers for Disease Control and Prevention's landmark Study on the Efficacy of Nosocomial Infection Control (SENIC) provided our first truly national portrait of surveillance for SSIs. ${ }^{1}$ Among SENIC's contributions was a robust risk index whose direct descendant we continue to use. ${ }^{2} \mathrm{~A}$ generation later, one would expect SSI surveillance methods to be well established, the epidemiology of SSIs to be well understood, and the research frontiers to be elsewhere.

And yet, in this issue of Infection Control and Hospital Epidemiology new reports from three continents speak to important unmet needs. ${ }^{3-5}$ Two of these articles address postdischarge surveillance, a problem that increasingly claims our attention as the duration of postoperative hospitalization shrinks, often to zero. A consensus statement in $1992^{6}$ asserted there was no validated method for conducting postdischarge surveillance, and this conclusion remains true.

The current report by Avato and Lai joins those of many predecessors ${ }^{7 \cdot 22}$ in noting that most infections first become manifest after discharge. This was true even though they studied coronary artery bypass graft surgery, a procedure whose postoperative length of stay is still measured in days rather than hours. This report illustrates the special circumstances currently required to establish an effective system, and it also indicates the magnitude of the effort. First, Avato and Lai were able to learn what the surgeons knew because they could establish ongoing coordination with the surgeons' offices. That, in turn, was possible because these offices were located in or near the hospital, allowing ongoing com- munication and review of office-based medical records as necessary. Second, the hospital's infection control department was able to make an ongoing commitment of the scarcest and most valuable of its resources, a large amount of practitioner time. If the University of Massachusetts experience is typical, then performing postdischarge surveillance for all coronary artery bypass surgery in the United States will absorb the fulltime effort of several hundred infection control practitioners. Comparable effort for all surgical procedures will require considerably more than the full-time effort of all current infection control professionals.

Thibon and colleagues remind us that the period of postdischarge risk often lasts longer than does postoperative care. Fortunately, the biology of SSI allows us to focus on the first 30 days for procedures that don't involve implanted prosthetic material. However, even 30 days is long, compared with the timing of follow-up office visits. So, we will need to incorporate the "when" of postdischarge surveillance into our methods and our lexicon. Survival analysis, the method adopted by the authors, is a good solution-if, as they point out, patients whose last follow-up occurs before 30 days are neither more nor less likely to experience infection during the remainder of the 30 days than patients whose last follow-up occurs at least 30 days after surgery. Is this true? We don't know. Is it a reasonable surmise? Possibly. In any event, the authors make a strong case for describing the duration of follow-up in any report of postdischarge surveillance.

The article by Russo and Spelman addresses the fact that all patients are not created equal regarding their baseline risk of infection. Our best case-mix adjuster, the National Nosocomial Infections Surveillance (NNIS) System risk index, ${ }^{2}$ achieves most of its separation through categorization of the risk associated with procedures, rather than with patients, who are classified as either "high 
risk" (ie, an American Society of Anesthesiologists score of 3 or greater) or "normal risk." This dichotomous approach clearly adds value, although the categorization is often subjective and prone to misclassification. ${ }^{23}$ The question that remains is, "Can we do better?" Clinical experience, a large literature identifying risk factors for infection, and surgeons with higher than average infection rates all tell us that we can. Russo and Spelman use their own experience in coronary artery bypass graft surgery to identify three patient-specific risk factors, obesity, diabetes, and noncardiac vascular disease, and then to create a risk index that predicts infection better than the NNIS System risk index. This study raises many important questions, including how much of the variation attributable to personal risk factors is captured by a risk index, how should one assess the generalizability of a new index, and how can one efficiently implement such an index when many institutions must obtain characteristics such as obesity by manual review of full-text medical records, if they are available at all?

Taken together, these three articles tell us much about what we know and what we don't know concerning the occurrence of SSIs. We certainly know that the answers to the questions "How many postoperative infections are there?" and "What is a patient's risk of infection?" depend on the definitions we use and where and how we search for them. We also know that we can substantially improve our ability to control for a patient's underlying risk of infection. And because of this, we can conclude that we will not be able to make meaningful comparisons-over time, between hospitals, and certainly between surgeons-until we can fairly characterize the riskiness of the patients as well as the procedures. Without such comparisons, we will have difficulty identifying best practices and we will not know the effect of our efforts to improve patient safety.

Therefore, we must continue to address the problems of infection detection and case-mix adjustment. However, we are likely to need additional approaches to these problems, because we are unlikely ever to have vastly greater resources, the prospect of much better healthcare information systems (ones that know body mass index, for example) in the foreseeable future is uncertain, and postoperative care is likely to become even more dispersed.

To answer the most important questions, for the healthcare system as a whole, for hospitals, for surgeons, and for individual patients, we should develop additional benchmarks that can be uniformly applied to essentially all instances of a given procedure, without regard to a specific facility's infection control budget, the willingness of its surgeons to participate in a surveillance program, or the location of postoperative care. To accomplish this in the short-term, we will need to use data systems and information that already exist-hospital discharge data, the billing records that payors (insurance companies and health plans, including Medicare) routinely process, and outpatient antibiotic exposure data obtained from phar- macy claims payment systems. These information systems have the advantage of being nearly universal, of using standard coding systems, and of being highly automated, so that the cost of extracting information about postoperative infections will be low. What will the tradeoffs be for using such systems? We surely can't use these information systems to identify the same cases that traditional surveillance does, but there are suggestions that they can identify enough risk-adjusted outcomes of interest to serve as a meaningful performance measure for our healthcare system as a whole and for hospitals, if not for individual surgeons or patients..$^{2427}$

We will continue to need traditional methods for identifying SSIs, and we should strive to improve the accuracy and interpretability of these methods. In addition, we should consider nontraditional uses of the large amount of data that surround us, to obtain the information we need to make surgery as safe as possible.

\section{REFERENCES}

1. Haley RW, Shachtman RH. The emergence of infection surveillance and control programs in US hospitals: an assessment, 1976. Am J Epidemiol 1980;111:574-591.

2. Mangram AJ, Horan TC, Pearson ML, Silver LC, Jarvis WL. Guideline for the prevention of surgical site infection, 1999. Infect Control Hosp Epidemiol 1999;20:247-278.

3. Avato JL, Lai KK Impact of postdischarge surveillance on surgical-site infection rates for coronary artery bypass procedures. Infect Control Hosp Epidemiol 2002;23:364-367.

4. Thibon P, Parienti JJ, Borgey F, et al. Use of censored data to monitor surgical-site infections. Infect Control Hosp Epidemiol 2002;23:368-371.

5. Russo PL, Spelman DW. A new surgical-site infection risk index using risk factors identified by multivariate analysis for patients undergoing coronary artery bypass graft surgery. Infect Control Hosp Epidemiol 2002;23:372-376.

6. Sheretz RJ, Garibaldi RA, Marosok RD. Consensus paper on the surveillance of surgical site infections. Am J Infect Control 1992;20:263270.

7. Brown RB, Bradley S, Opitz E, Cipriani D, Pieczrka R, Sands M. Surgical wound infections documented after hospital discharge. Am J Infect Control 1987;15:54-58.

8. Burns SJ. Postoperative wound infections detected during hospitalization and after discharge in a community hospital. Am I Infect Control 1982;10:60-65.

9. Byrne DJ, Lynce W, Napier A, Davey P, Malek M, Cuschieri A. Wound infection rates: the importance of definition and post-discharge wound surveillance. J Hosp Infect 1994;26:37-43.

10. Couto RC, Pedrosa TM, Nogueira JM, Gomes DL, Neto MF, Rezende NA. Post-discharge surveillance and infection rates in obstetric patients. Int J Gynaecol Obstet 1998;61:227-231.

11. Ferraz EM, Ferraz AA, Coelho HS, et al. Postdischarge surveillance for nosocomial wound infection: does judicious monitoring find cases? $\mathrm{Am} \mathrm{J}$ Infect Control 1995;23:290-294.

12. Holtz TH, Wenzel RP. Postdischarge surveillance for nosocomial wound infection: a brief review and commentary. Am I Infect Control 1992;20:206-213.

13. Keeling NJ, Morgan MW. Inpatient and post-discharge wound infections in general surgery. Ann R Coll Surg Engl 1995;77:245-247.

14. Kent P, McDonald M, Harris O, Mason T, Spelman D. Post-discharge surgical wound infection surveillance in a provincial hospital: follow-up rates, validity of data and review of the literature. Aust $N Z J$ Surg 2001;71:583-589.

15. Law DJ, Mishriki SF, Jeffery PJ. The importance of surveillance after discharge from hospital in the diagnosis of postoperative wound infection. Ann R Coll Surg Engl 1990;72:207-209.

16. Manian FA, Meyer L. Comprehensive surveillance of surgical wound infections in outpatient and inpatient surgery. Infect Control Hosp Epidemiol 1990;11:515-520.

17. Pearce P, McKenzie M, Taylor G. Wound infections in orthopedic surgery: effect of extended surveillance on infection rate. Can J Surg 1991;34:31-35.

18. Polk BF, Shapiro M, Goldstein P, Tager I, Gore-White B, Schoenbaum 
SC. Randomised clinical trial of perioperative cefazolin in preventing infection after hysterectomy. Lancet 1980;1:437-441.

19. Poulsen KB, Meyer M. Infection registration underestimates the risk of surgical wound infections. J Hosp Infect 1996;33:207-215.

20. Reimer K, Gleed G, Nicolle LE. The impact of postdischarge infection on surgical wound infection rates. Infect Control 1987;8:237-240.

21. Sands $K$, Vineyard G, Platt R. Surgical site infections occurring after hospital discharge. I Infect Dis 1996;173:963-970.

22. Santos KR, Bravo Neto GP, Fonseca IS, Gontijo Filho PP. Incidence surveillance of wound infection in hernia surgery during hospitalization and after discharge in a university hospital. $J$ Hosp Infect 1997;36:229-233.

23. Haynes SR, Lawler PG. An assessment of the consistency of ASA physical status classification allocation [see comments]. Anaesthesia 1995;50:195-199.
24. Kaye KS, Sands K, Donahue JG, Chan A, Fishman P, Platt R. Preoperative drug dispensing predicts surgical site infection. Emerg Infect Dis 2001;7:57-65

25. Sands K, Vineyard G, Livingston J, Christiansen C, Platt R. Efficient identification of postdischarge surgical site infections using automated medical records. J Infect Dis 1999;179:434-441.

26. Sands K, Yokoe D, Hooper D, Tully, Platt R. Multi-institutional comparison of surgical site infection surveillance by screening of administrative and pharmacy data. Presented at the 9 th Annual Meeting of the Society for Healthcare Epidemiology of America; April 18-19, 1999; San Francisco, CA Abstract M35.

27. Yokoe DS, Christiansen CL, Johnson R, et al. Epidemiology of and surveillance for postpartum infections. Emerg Infect Dis 2001;7:837841. 